\title{
THE ANOMALOUS PROPERTIES OF POLYSILOXANE FILMS
}

\author{
VLADIMÍR RYŠANEK \\ Czech Technical University, Prague, Czechoslovakia
}

\begin{abstract}
An electron beam was used to create thin polysiloxane films from methylphenylsiloxane and the anomalous properties of permittivity and temperature dependence, the resistivity dependence on humidity and the permittivity dependence on pressure of air or argon, was examined. These anomalous properties can be potentially applicable to humidity probes, pressure gauges and for miniature capacitors.
\end{abstract}

\section{INTRODUCTION}

An electron beam was used to create thin polysiloxane films and the anomalous electrical properties were observed. In this paper the dependence of resistivity on the humidity, the temperature dependence and the change of capacity with different atmosphere and pressures are described.

\section{PREPARATION TECHNIQUE}

The preparation of polysiloxane layers was effected by using vacuum equipment with an in-built electron source controllable siloxane evaporation source and a substrate base with changeable temperature. The electron beam was deflected and controlled by sawtooth generators. Experiments were made with this equipment using acceleration voltage of $1,5 \mathrm{kV}$ and beam current of up to $1 \mu \mathrm{A}$. The films were condensed from vapours of heated methylphenylsiloxane. By changing the electron bombardment the physical properties of the materials from liquid to solid siloxane were obtained. Substrates were made from glass provided with silver electrodes.

\section{EXPERIMENTAL RESULTS}

The permittivity of films depends on the thickness and on the preparation conditions. The dependence of relative permittivity on the thickness is depicted in Figure 1. The dielectric properties of layers also depended on the temperature. Typical temperature characteristics of permittivity and dielectric loss angle are depicted in Figure 2. The resistance of the layers

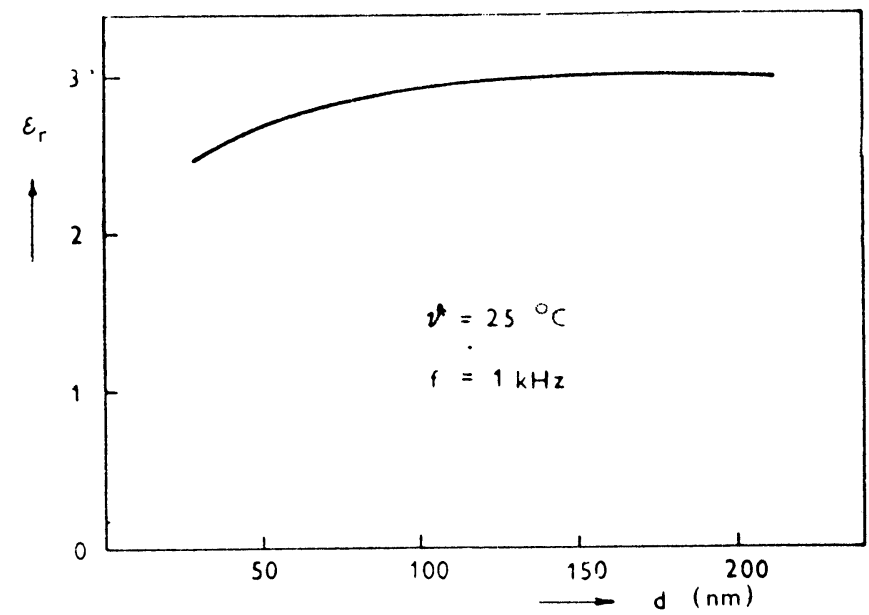

FIGURE 1 The dependence of the permittivity on the thickness.

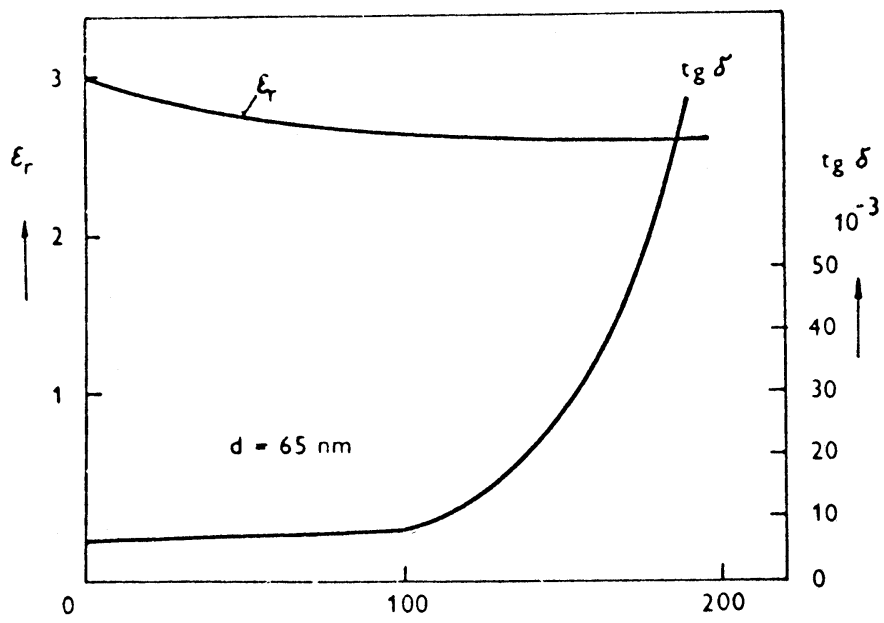

FIGURE 2 The dependence of the $\varepsilon_{\mathrm{r}}$ and $\operatorname{tg} \delta$ on the temperature. 


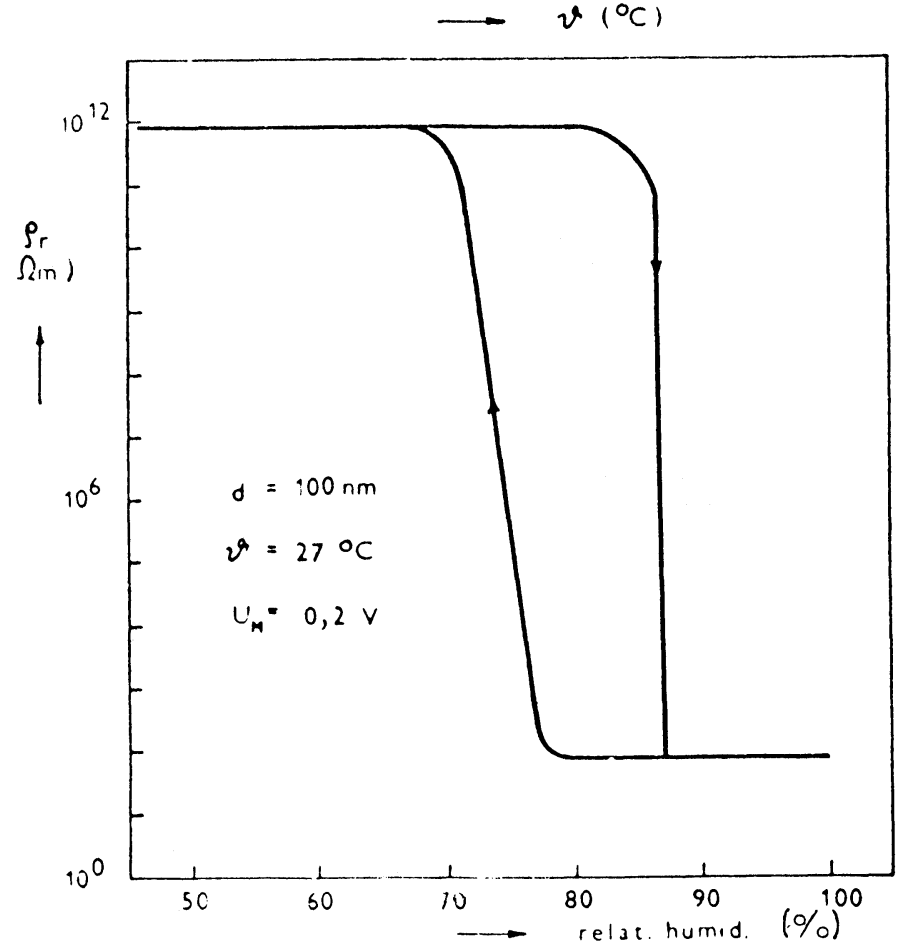

FIGURE 3 The dependence of the resistivity on the relative humidity.

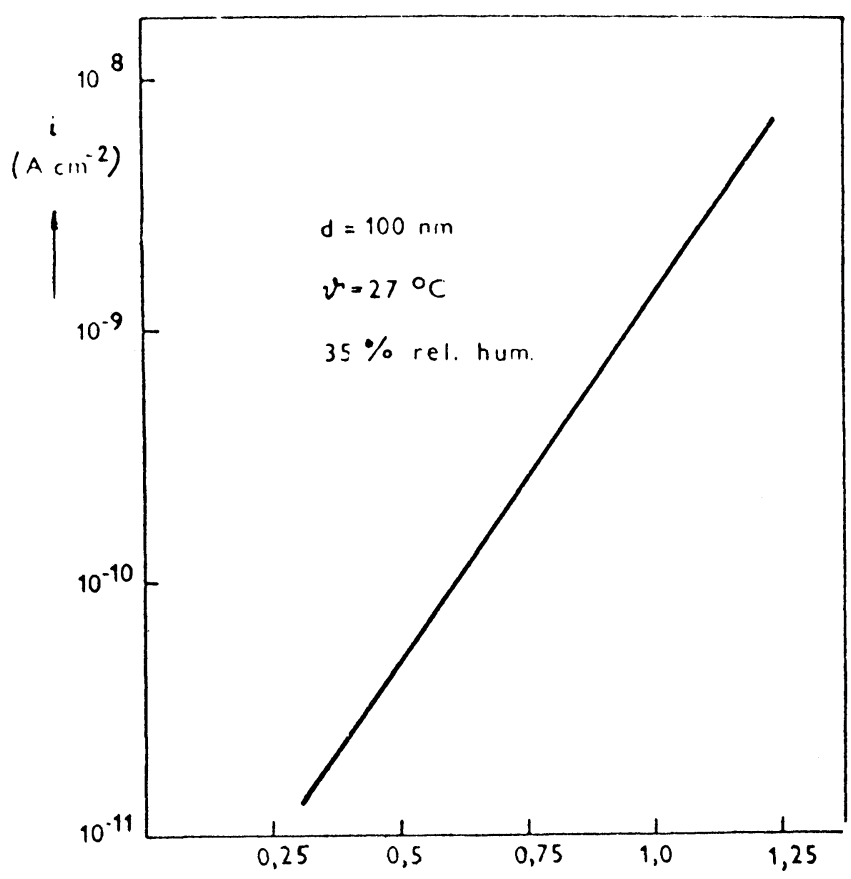

FIGURE 4 The Schottky conductivity. depended strongly on air humidity. In dry air the resistance of layers was very high $\left(\sim 10^{12} \Omega \mathrm{m}\right)$, but after exposure to atmosphere with higher relative humidity, the resistance decreased by 11 decades, as can be seen in Figure 3. This change is more or less reversible. In the layers, Schottky-conductivity was observed as can be seen from the characteristics in Figure 4. During our investigation of the temperature dependence of the mechanical properties of the layers we found that after heating in air and vacuum, the mechanical hardness initially increased and afterwards slowly declined (Figure 5). Some of the measurements have proved

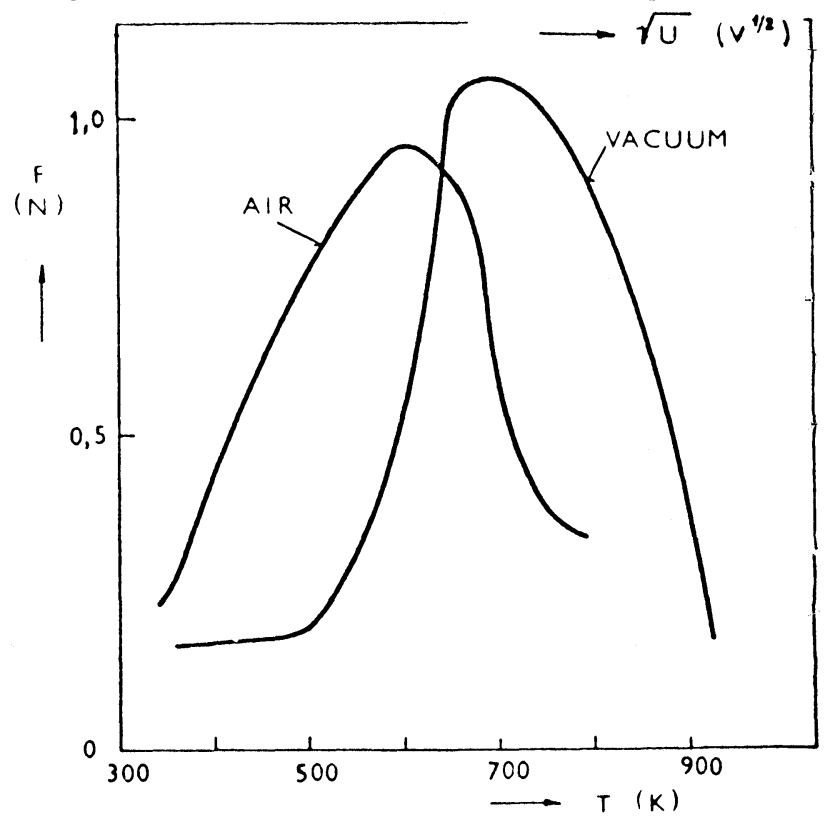

FIGURE 5 Hardness as a function of temperature.

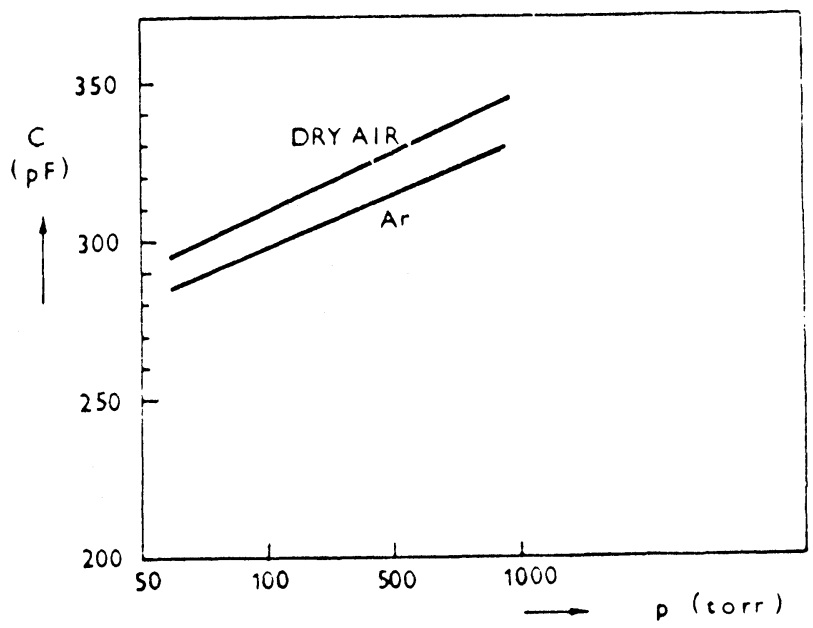

FIGURE 6 The dependence of the capacity on air or Argon pressure. 
that such layers are sensitive not only to humidity, but also to atmosphere pressure changes. The layers have shown a capacitance change of $\sim 10 \%$ when measured in $1 \mathrm{~atm}$. dry argon compared to the value in vacuum. This dependence is depicted in Figure 6.

\section{CONCLUSION}

Present results show, that layers of siloxane have unusual properties and can be produced in different thicknesses during one deposition, avoiding the necessity of using masking techniques.
The applications of these types of films are to the possible separation layers for protection of integrated circuits, and in humidity probes and pressure gauges. The dielectric properties of the layers are acceptable for miniature capacitors.

\section{REFERENCES}

1. V. Ryšánek, Electrotechnický casopis XXII, No. 9, pp. 694-705 (1971).

2. Y. Tauri, S. Denda, H. Baba, S. Miyauchi and K. Tanaka, Microelectronics and Reliability, 8, 1, pp. 101-111 (1969). 

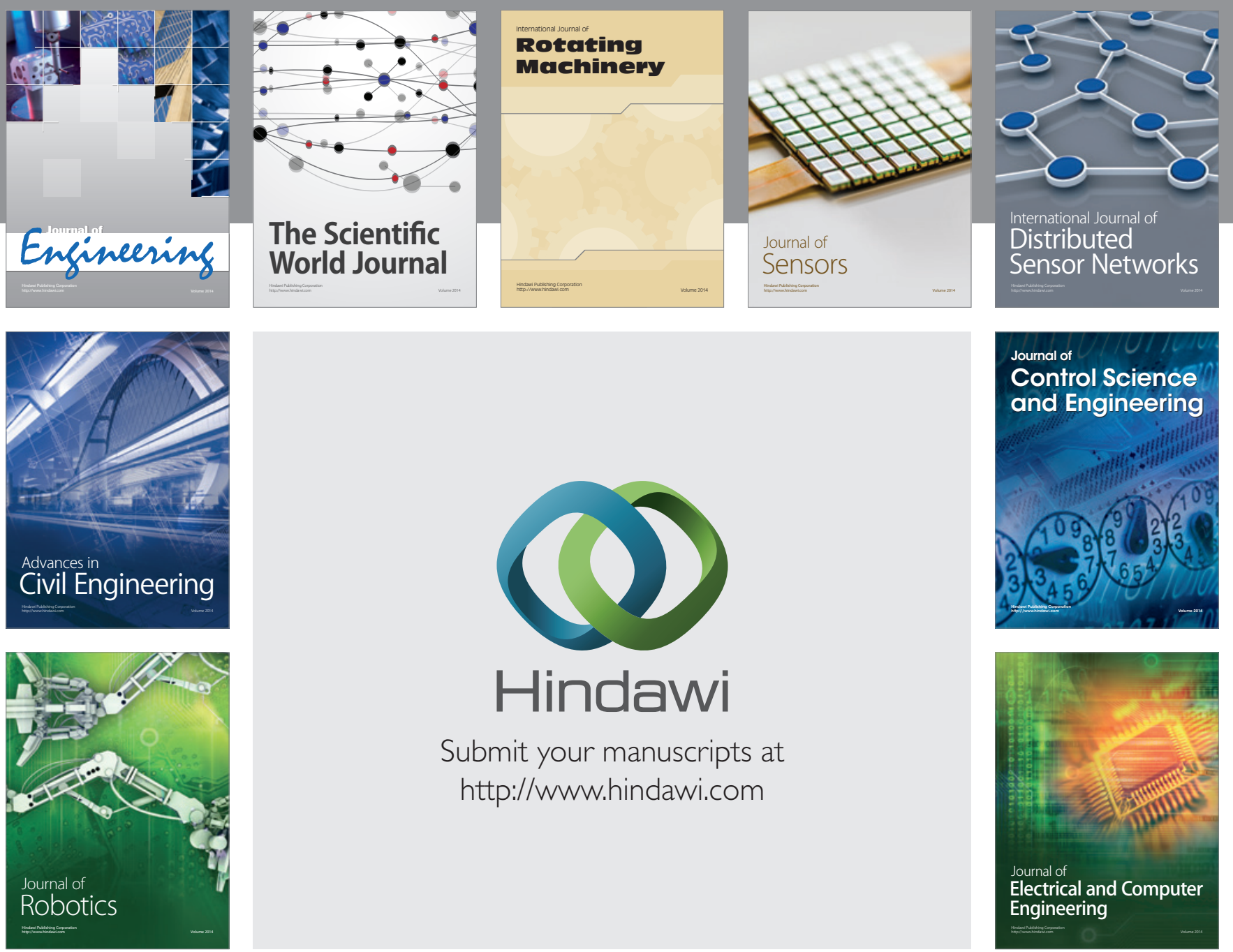

Submit your manuscripts at

http://www.hindawi.com
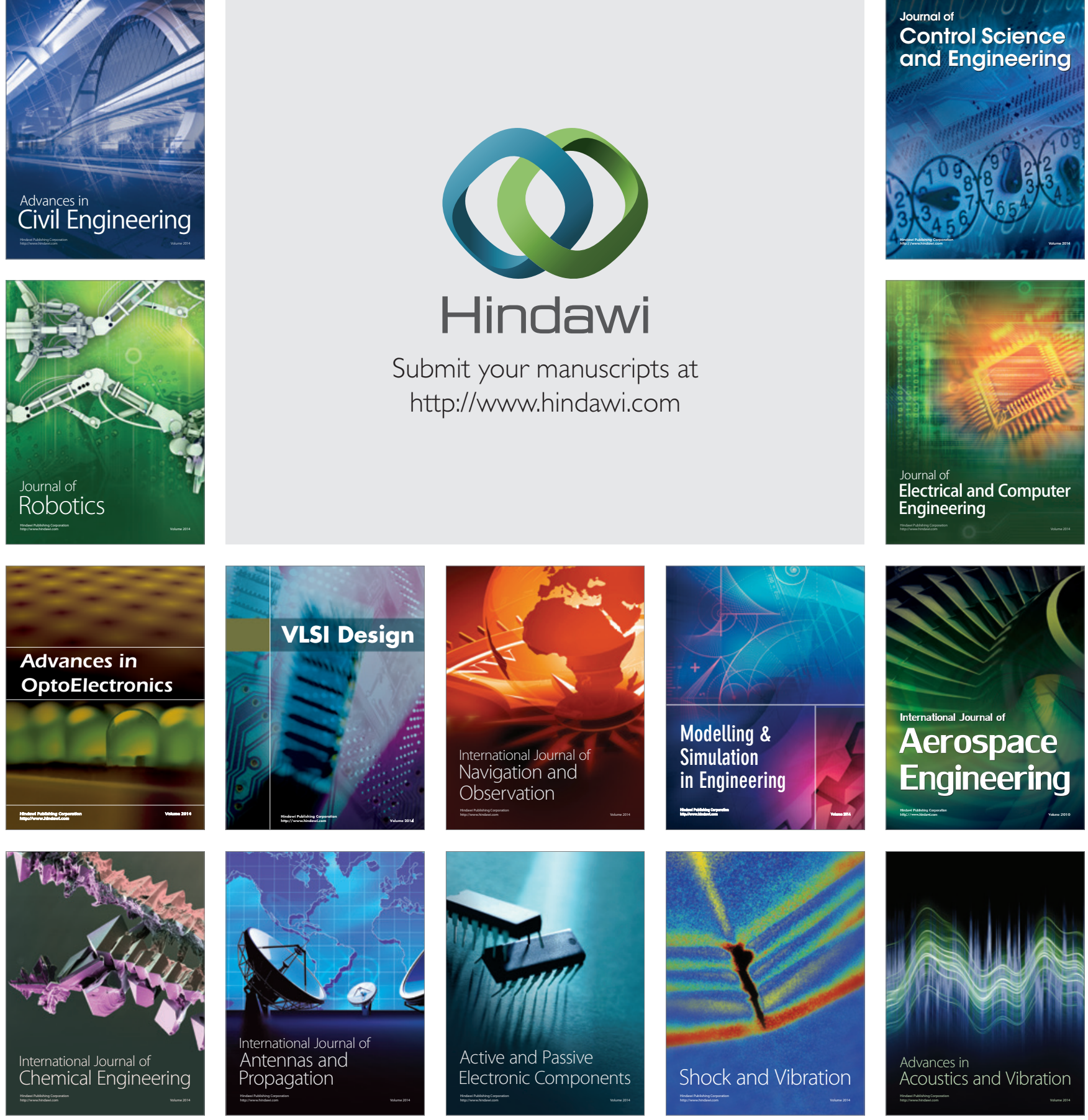